\title{
Gauging Cameroon's Resilience to the COVID-19 Pandemic: Implications for Enduring a Novel Health Crisis
}

\begin{abstract}
Purpose

This article examines Cameroon's health service resilience in the first five months (March-July 2020) of the COVID-19 outbreak. The motive is to diagnose suboptimal performance in sustaining health care services during the pandemic in order to identify areas for improvement as well as draw lessons for the future.
\end{abstract}

\section{Design/methodology/approach}

This is principally qualitative, exploratory, analytical and descriptive research that involves the collation of empirical, primary and secondary data. A conceptual framework (Health Systems Resilience for Emerging Infectious Diseases) provides structure to the article and an anchor for interpreting the findings. The research validity has been established by analysing the aims/objectives from multiple perspectives in the research tradition of triangulation.

\section{Findings}

Cameroon has exerted much effort to combat the COVID-19 pandemic. Yet, several constraints and gaps exist. The findings reveal limitations in Cameroon's response to the COVID-19 pandemic in the provision of fundamental health care services under contextual themes of health infrastructure/medical supplies, human capital, communication/sensitisation/health education, governance and trust/confidence. Analysis of the identified impediments demonstrate that Cameroon's healthcare system is not resilient enough to cope with the COVID-19 pandemic and provides several insights for enhanced response as the pandemic accelerates in the country.

\section{Originality}

This is one of the first scholarly articles to examine how Cameroon's healthcare system is faring in COVID19 combat. Underscored by the novel Health Systems Resilience for Emerging Infectious diseases (HSREID) model, this article provides initial insights into Cameroon's resilience to COVID-19 with a view to enhancing the health system's response as the pandemic unfolds and strengthens readiness for subsequent health crises.

Keywords: Cameroon, COVID-19, Governance, Resilience, Pandemic, Health System, Sensitisation, Trust.

\subsection{Introduction}

The COVID-19 pandemic caused by the coronavirus disease that was initially detected in 2019 has conspicuously exposed the unprepared state of the world's health systems. COVID-19 threatens to disproportionately affect the least developed countries with potentially dire ramifications for human health and the economy (UN, 2020). In fact, resource scarce countries are relatively far slower than developed countries to detect, communicate, respond to and recover from outbreaks of communicable viruses/disease (Kluberg, et al., 2016).

A case in point is the 2014-2016 West Africa Ebola outbreak that over-whelmed the fragile health systems of Sierra Leone, Guinea and Liberia, exposing the complex challenges involved in the fast detection, infection tracing, quarantine and safety caring for critically sick patients (Madhav, 2018). Despite the global research effort triggered by the Ebola virus outbreak to understand various aspects of the epidemiology and response to the epidemic, a huge gap exists on integrating public health resilience in crisis response in Lower Middle-Income Countries (LMIC) (WHO, 2018). 
As the COVID-19 pandemic evolves, Cameroon has been afflicted with one of the highest numbers of confirmed cases in sub-Saharan Africa (OCHA, 2020). The pandemic bears heavily on Cameroon because it would compound the humanitarian crises already affecting the country like the Boko Haram insurgency and the Anglophone armed conflict that has been raging in the North West and South West Regions for the past four years.

The main aim of this article is to examine the resilience of Cameroon's heath system response to COVID19. The objectives are to diagnose challenges in sustaining COVID-19 health services during the first five months (March to July) of the pandemic and provide some key lessons for the future.

\subsection{Cameroon's Health Profile: A Brief Review}

Cameroon is a LMIC located between Central/Western Africa with a population of around 25,876,380 (2019 estimate) living in 10 administrative regions (World Bank, 2020). Cameroon's health facilities are stratified into three levels: Central (Referral, Central, General and University Teaching Hospitals), Intermediate (Regional Hospitals) and Peripheral (Sub-Divisional/District Medical Centres, District Hospitals and Health Centres/Clinics/Cabinets (WHO, 2016; MPH, 2016).

A review of Cameroon's Health Sector Performance in 2015 revealed key health indicators. For instance; the doctor-patient ratio is one doctor per 50,000 inhabitants in rural areas (Kindzeka, 2018); just 5.01\% of the state budget is allocated to health; prevalence of HIV has dropped to $4.3 \% ; 63.1 \%$. of functional health facilities are within an hour's walk from the populace; malarial hospital mortality is $22.4 \%$; $6 \%$ of deaths are linked to tuberculosis (WHO, 2016). Life expectancy at birth is 57.3 years, communicable diseases were responsible for around $41.1 \%$ of deaths in 2013 and non-communicable diseases are on the rise and accounted for 31\% of all deaths in 2014 (Agbor and Tambi, 2014; NOPH/MPH, 2017). The cost of healthcare is very high and only $6.5 \%$ of Cameroonians have accessed to health insurance schemes (Nde, et al., 2019).

Despite the poor performance of Cameroon's health sector, progress in meeting the health system objectives were recorded in mitigating the spread of HIV/AIDs; increasing Yellow Fever immunisation coverage and health facilities within one hour's walk from the population; and reducing deaths linked to tuberculosis and neonatal mortality (WHO, 2016; NOPH/MPH, 2017). Theoretically, the health system is decentralised. Operationally though, a centralised structure exists to the detriment of the lower administrative units (Tandi, et al., 2015). This has huge implications for scaling up interventions during outbreak of infectious diseases like COVID-19.

\subsection{The Coronavirus Pandemic in Cameroon}

Whilst there is paucity of literature on the COVID-19 pandemic in Cameroon, the few paint a daunting picture in the provision of adequate health care. The first cases of COVID-19 in Cameroon was reported on March 6, 2020. On March 17, 2020, the government instituted the first set of containment measures to control the virus. Subsequent measures were announced progressively with most eased just after 6 weeks of the initial measures amidst concerns the infection rate was escalating (Tamfu and Lietbouo, 2020). Early insights into the management of the COVID-19 pandemic have revealed several constraints including in financing; hence the government solicited for public donations and set up a National Solidarity Fund for the pandemic response (MPH, 2020). The International Monetary Fund provided US\$ 226 million to help the government manage the coronavirus response (IMF, 2020).Yet, significant challenges exist in the provision of healthcare for COVID-19. Ngeh and Kuaban (2020) identified challenges in healthcare provision in setting up isolation centres to quarantine infected cases; triaging patients to detect infected cases; inadequate protective equipment for healthcare workers, the populace, and in supporting the rehabilitation of survivors. The number of laboratories capable of testing for COVID-19 in the whole country are limited (OCHA, 2020). Just 10 laboratories exist for a population of 26 million and consequently a relatively low number of COVID-19 tests are being carried out (Njonnou et al., 2020). 
Furthermore, the government has insufficient capacity to scale-up COVID-19 intervention coverage all over the country and the cost for treating the virus is high for the population (HRW, 2020).

\subsection{Resilience in the Context of Health Systems}

\subsection{Resilience as a Concept}

Resilience is a concept that has been the lexicon of numerous disciplines including ecology, natural hazards/disasters, psychology, politics, economics and engineering etcetera. The concept has evolved and broaden over time with mushrooming literature that has made the term confusing and without consensus on its application (Turenne et al., 2019). The 2015-30 Sendai Framework for Disaster Risk Reduction stresses the relevance of building health resilience in disaster risk reduction (UNISDR, 2015). Its predecessor, the Hyogo Framework for Action (HFA) 2005-2015 underscored the relevance of resilience in its subtitle "Building the Resilience of Nations and Communities to Disasters" (UNISDR, 2005). The UN defines resilience as "the ability of a system, community or society exposed to hazards to resist, absorb, accommodate to and recover from the effects of a hazard in a timely and efficient manner, including through the preservation and restoration of its essential basic structures and functions" (UNISDR, 2009, p.24).

\subsection{Conceptualising Health Systems Resilience (HSR)}

The definition of health systems resilience (HSR) is imprecise albeit strategically useful. Most definitions of HSR focus on preparedness and response of the health systems to severe shocks, and the ability of the systems to cope with, absorb, adapt or resist any changes caused by the shocks (Barasa, et al., 2017). The definition has broadened to encompass relevance in health systems strengthening for universal health coverage and health security (Kutzin \& Sparkes, 2016); societal response to major shocks or health crises (Castleden et al., 2011); managing enduring and predictable system stresses and strains (Barasa, et al., 2017) and as an objective of health systems (European Commission, 2014).

Dissonance in conceptualising HSR can be confusing for authorities and policymakers seeking to apply the concept in monitoring health systems performance especially during a health crisis like the COVID-19 pandemic. For operational purpose, the WHO has harmonise usage of the phrase and defined HSR as "the ability to prepare for, manage (absorb, adapt and transform) and learn from shocks" (WHO, 2020, p.8). Shocks are considered sudden and extreme/severe changes that can impact on a health system like hurricanes, the Ebola/Zika virus including the COVID-19 pandemic (WHO, 2020), which is the empirical focus of this article.

\subsection{HSR in Africa}

HSR in Africa has been examined in contexts vulnerable to conflict and crises. A study of the HSR of Yobe State (Nigeria) following the disruption of its health service due to the Boko Haram insurgency found that population migration, the suspension of programmes providing external technical assistance and transport restrictions substantially restricted access to health provision. Nevertheless, the political will of the Yobe State government to strengthen health provision helped the State's health systems functions to recover. (Ager et al., 2005). The 2013 Ebola outbreak in West Africa rapidly spread from Guinea into neighbouring Liberia and Sierra Leone because these countries had a limited health systems capacity to cope with the epidemic - weak governance, logistics, infrastructure, drug supply systems, surveillance, and health information; insufficient numbers of qualified healthcare workers; government expenditure on health was low whereas private health expenditure was high; and sub-optimal organization and management of health services (Kieny et al., 2014). These two cases of HSR provide lessons that could inform those in other contexts facing similar conflict/health crisis-related challenges including the COVID-19 pandemic.

\subsection{Assessing HSR}


Informed by the COVID-19 pandemic and other health crises, the WHO has identified strategies for enhancing HSR in the areas of governance (effective and participatory leadership, coordination of activities, organisational learning culture, information systems and flows, surveillance); financing (flexibility in accessing monetary resources, health system funding, health coverage); resources (human/physical resources, ability to scale-up resources, motivation in the workforce); and service delivery (flexible/ alternative approaches to healthcare delivery) (WHO, 2020). This framework is similar to that used in this article.

While HSR has gained popularity in global public health, the practical application does not match the theoretical foundation of the concept, which has been criticised as a top-down approach that obscures adequate response to epidemics (Martineau, 2016). Critics of the concept have suggested the idea of "everyday resilience" that stresses the relevance of health workers having access to resources and capacities daily (Barasa et al., 2017); a model underpinned by a systems whose management and key health actors have the capacities to respond to change (Blanchet et al., 2017) and a health system that focuses on building the trustworthiness of health actors and on improving its daily operations (Martineau, 2016).

Notwithstanding, HSR has gained major traction in theoretical discourse and empirical enquiry as researchers, policy makers and governments strive to understand, identify and predict mechanisms that influence the resilience of health systems in the context of adversity (ReBuild, 2016). This article has a similar focus with the resilience of Cameroon's heath system to the COVID-19 pandemic at the core of the analysis.

\subsection{Conceptual Framework}

A conceptual framework approach has been adopted to provide this article with a common reference point, better clarity and clear structure. Several conceptual frameworks for HSR exist that address a variety of disaster, emergency and crises situations. For instance, Olu (2017) reflects on the nexus between the health system framework and disaster risk management and suggests health system building blocks as a conceptual framework for public health DRM Africa. The WHO has suggested a number of HSR frameworks; one is an operational framework for building climate resilient health systems that has guidance on how health systems should systematically address the challenges posed by climate variability and change (WHO, 2015). Recently, the WHO distilled, identified and mapped measures to strengthen resilience with key health systems functions; emphasising that the application of the measures is dependent on specific country contexts, type/severity of shock or crises (WHO, 2020). A novel framework, the Health System Resilience for Emerging Infectious Diseases (HSREID) is predicated on how the health systems in LMICs respond to emerging infectious diseases (Palagyi, et al., 2019). Whilst the core components of these HSR frameworks overlap in areas like optimal allocation and combination of resources to maximise healthcare output, responsiveness to stakeholders and maximising health promotion interventions across a broad range of activities, their application is tailored to specific shocks or crises. The HSREID has been chosen for this research since it aligns with the research aims/objectives in identifying key features that would confer resilience to the health systems in LMICs in the context of an emerging/novel health crisis like COVID-19.

\subsection{Health Systems Resilience for Emerging Infectious Diseases (HSREID)}

The HSREID framework constitutes six constructs of a health system that has been divided into four hardware and two software elements. The four hardware constructs comprise of (1) Infrastructure and medical supply; (2) Human capital/workforce, (3) Surveillance and (4) Communication mechanisms while the software constructs are (1) Governance and (2) Trust (see Table I; Palagyi et al. 2019).

\section{Table I here}

Table I shows the core/main systems constructs, their related elements and examples of activities/resources that underpin the HSREID framework (Palagyi et al., 2019). This framework provides a baseline for analysing the health systems resilience of LMICs and has been applied to gauge Cameroon's resilience to 
the COVID-19 pandemic in this research. Furthermore, the framework has influenced both the design of the empirical enquiries and the structure of the main findings.

\subsection{Methodology}

This research is predominantly exploratory and adopts a mixed method strategy involving the collection of qualitative and quantitative data. Empirical data was generated via a survey administered online between June $9^{\text {th }}$ and July $30^{\text {th }}, 2020$ that received 162 responses ( 38 from health workers who were the target sample unit and 124 from the public). Sample selection was initially purposive, and subsequently, the respondents used a snowballing technique to roll-out the survey to their networks. The ethical research tradition of anonymity, confidentiality and voluntary participation underpin the data collection process (Hammarberg et al., 2016).

The frontline health workers who constitute the primary informants to this research come from eight of Cameroon's 10 administrative regions. They work in General Hospitals ( $=20)$, District Hospitals $(\mathrm{N}=9)$, District Health Centres ( $N=7$ ), University Hospitals $(\mathrm{N}=2)$; are medical doctors $(\mathrm{N}=24)$, administrators of medical facilities $(\mathrm{N}=6)$, nurses $(\mathrm{N}=6)$ and health science teachers/lecturers $(\mathrm{N}=2)$. The design of the survey was structured to capture both qualitative and quantitative inputs and to elicit responses on key themes/constructs in the HSREID framework relevant to COVID-19 health care in Cameroon.

Primary, secondary and grey data was freely sourced from the websites of governmental agencies/ministries, humanitarian agencies, NGOs, the media and scholarly articles. The data sources included reports on regular COVID-19 briefings; plans, policies, guidelines for COVID-19 treatment; press/media reports; situation, country and project reports of humanitarian agencies. These data sources complemented the empirical data in the analysis to enhance the validity of the results .

The survey could have been complemented with key informant interviews, which was difficult to organise due to the hectic schedules of potential respondents, and what some senior officials considered to be a sensitive topic. A larger sample would have enhanced the data; however, some potential respondents were sceptical, reluctant and slow to respond. Hence, the sample size/scope was determined by the availability of respondents and their willingness to respond to the survey enquiries on time.

\subsection{Findings}

\subsection{Health Care Infrastructure and Medical Supply}

The provision of COVID-19 medication has been challenging. Most healthcare respondents intimated that medication and oxygen for COVID-19 patients have not always been available (Figures 1 and 2). A similar finding recorded shortages in disinfectants, protective gear for nurses/doctors, thermometers, medicines including ventilators and oxygen (HRW, 2020). Most health facilities with intensive care units are in the Centre and Littoral Regions while the other regions have limited ability to provide intensive care for COVID-19 patients. 


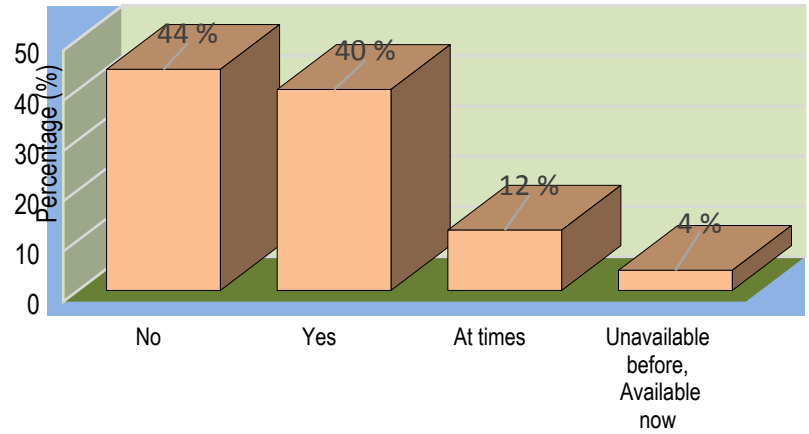

Figure 1: Response to whether medication for COVID-19 patients has always been available

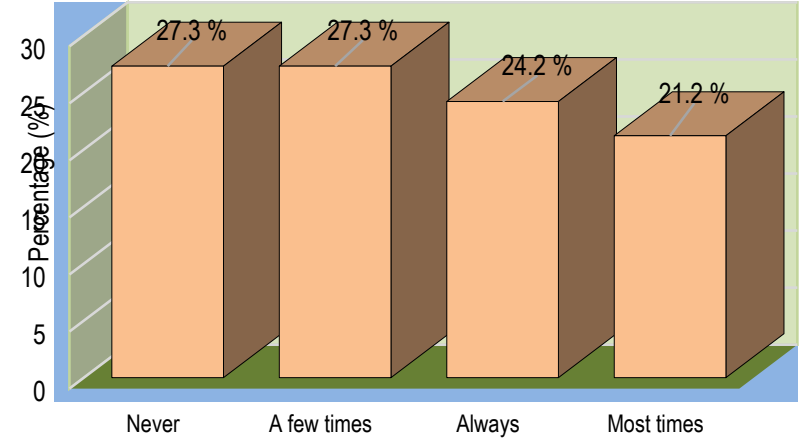

Figure 2: Response to whether Oxygen for COVID-19 patients has always been available

Regarding safety, $50 \%$ of the respondents had never had an adequate amount of personal protection equipment (PPE) since the pandemic started. The remaining half have either had it most of the time, sometimes or always as shown in Figure 3. PPE are mostly and always available to health workers in the Centre and Littoral Regions, while $63 \%$ of health workers in the North West, South West, and East regions combined have never had adequate PPE. Indeed, PPE was hardly received in time especially at the beginning of the pandemic.

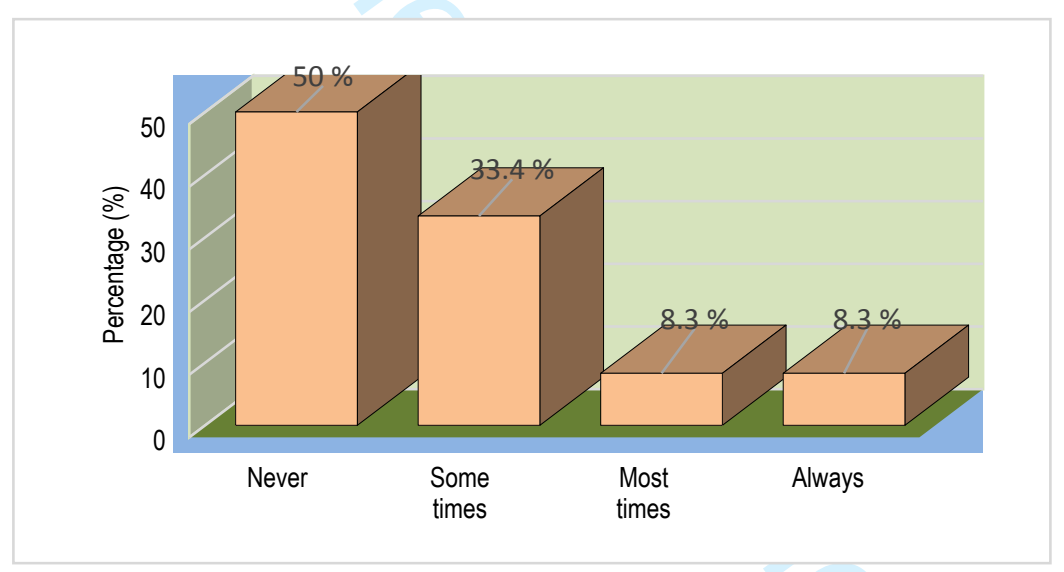

Figure 3: Availability of adequate amount of PPE

Respondents with limited access to PPE have safety concerns getting close to COVID-19 patients. In addition, the research captured the disproportionate distribution of COVID-19 resources from a medical doctor who heads a District Hospital, hear him, "...most of the resources are dedicated to the centre region...even when the limited resources are allocated to the other regions, they are also highly centralised at the regional level leaving the districts to fend for themselves...". Nevertheless, some respondents admitted they are now receiving PPE more regularly than before.

Most respondents highlighted challenges in the general identification and treatment of COVID-19 patients at the start of the pandemic, citing delays in sample collection from symptomatic patients, diagnosis, providing test results, data transmission, slow pace in creating isolation/quarantine wards and off-hospital centres with many not well-equipped including lack of enough bed capacity.

Enquiries on the symptoms required to test for COVID produced the results shown in figure 4. Interestingly, not all cases presenting COVID symptoms are screened; as revealed by $38.9 \%$ of the respondents. The reasons provided are lack of screening equipment and that cases are transferred to testing centres/health clinics. Furthermore, more than one symptom is needed to do the test, test kits are rationed, and tests are 
only done if the symptoms are severe. Ineffective triage of patients in the evolving pandemic has been mentioned by Ngeh and Kuaban (2020).

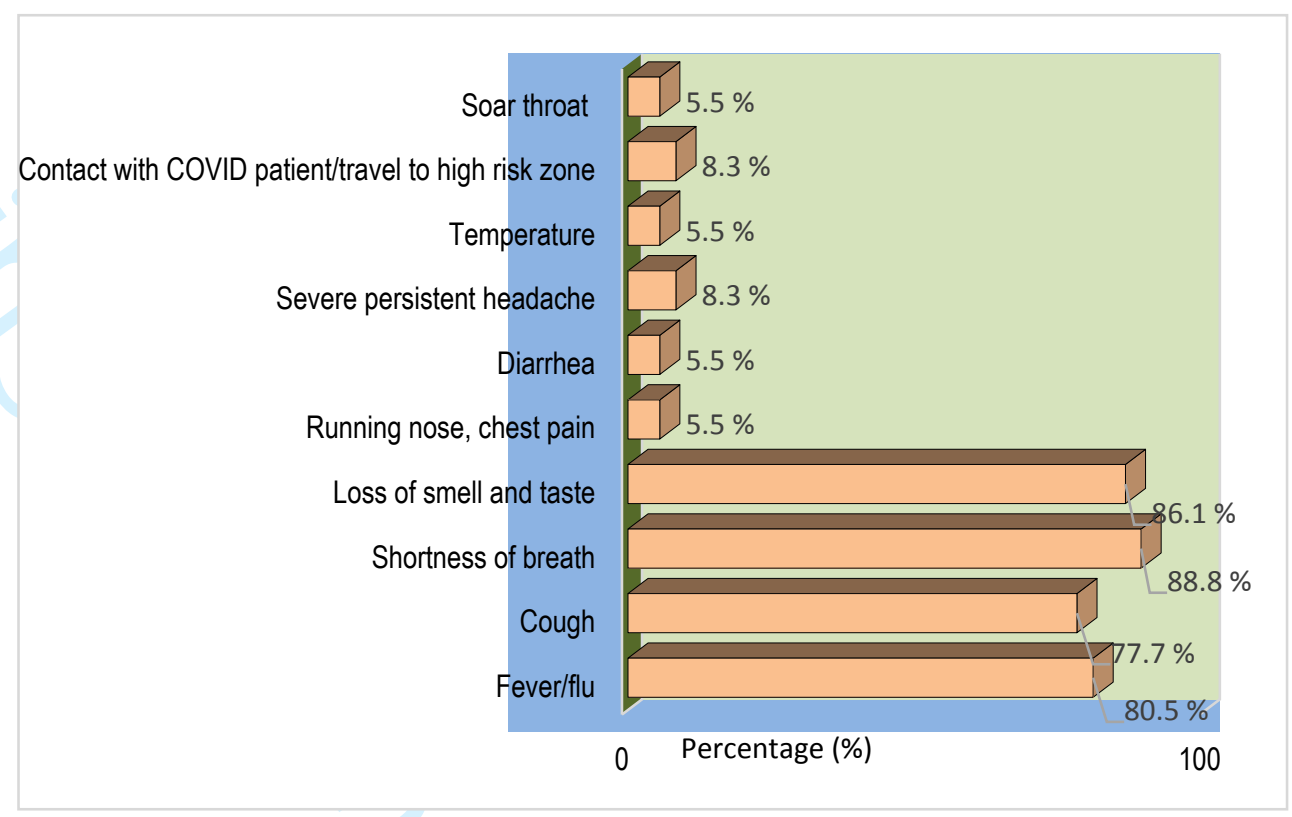

Figure 4: Presenting symptoms requiring testing for COVID-19

Nevertheless, the data shows significant improvements in treatment protocols and procurement of essential medicine and equipment for patient care as the pandemic unfolds. The following enhancements were documented from $70.8 \%$ of the respondents: additional procurement of ventilators, anaesthetics, steroids, new ambulances; more oxygen saturation checks; addition of anticoagulants and anti-inflammatory drugs to the treatment process; decentralisation of COVID-19 treatment; more treatment centres/testing facilities; reduction in waiting times for testing and restricted visits to hospitalised patients. These changes demonstrate governments' commendable efforts to improve patient care for COVID-19.

\subsection{Human Capital Development}

$33.3 \%$ and $66.7 \%$ of the healthcare respondents had received and not received training for COVID-19 care respectively. Most of those who had not been trained (59.3\%) work in the Anglophone region (Figure 5). Other than the Centre Region, the North West Region also has one of the highest numbers of trained health care workers (Figure 6). Nevertheless, the data shows an almost equal percentage of trained and untrained health workers all over the country. Some untrained respondents said they updated their knowledge on COVID-19 care by reading the WHO websites, and guidance documents provided by MPH. A question that teased out basic training on how to wear PPE found that $50 \%$ of the health actors had been trained while 50 had not.

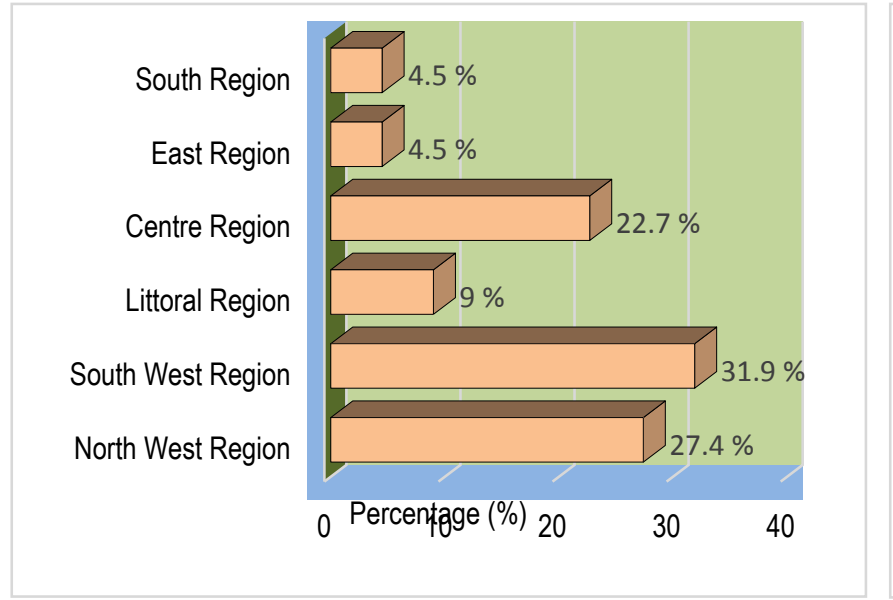

Figure 5: Health workers not trained for COVID-19 care

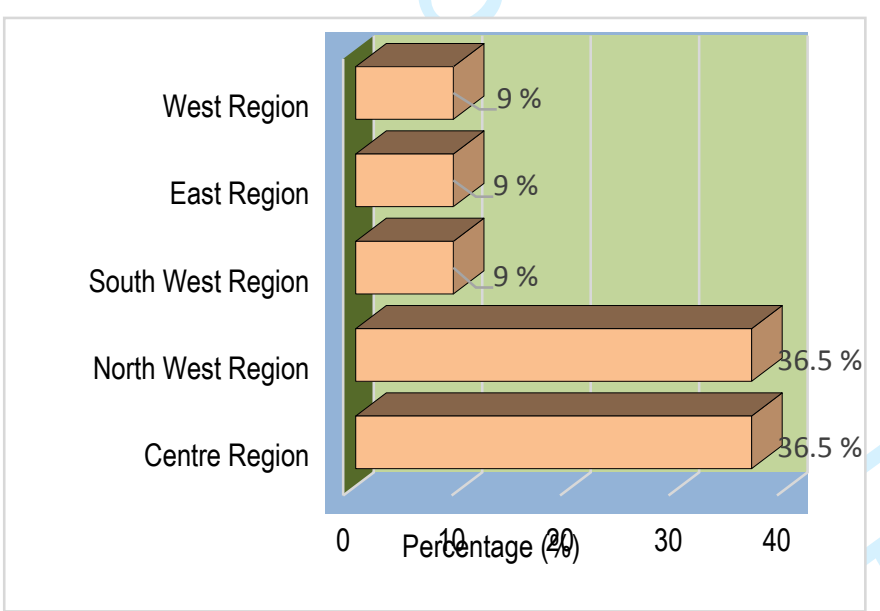

Figure 6: Health workers who have received training for COVID-19 care 
The quality of training obtained varied. Some respondents described the training as "...onsite crash course...," "...one day course at health facility...," "... been briefed on COVID-19 through regional meetings..." Most health workers residing in the nation's political and economic capitals have received more formal training from the WHO and/or MPH. A senior health staff remarked about disproportionate training, stating that, "...district rapid response teams have not sufficiently been provided with capacity building...most district medical officers and hospital directors have resorted to using online contents from various sources like WHO and CDC to auto-build their own capacities and subsequently that of their staff."

$77 \%$ of the health workers felt they needed more training for the following reasons: respondent not yet trained; refresher, formal and more practical training needed; need new knowledge on COVID-19 as it accrues; and the need for more elaboration on specific aspects-diagnosis, patient pathways/treatment, psychosocial management of patients, training colleagues, disinfection of instruments/beddings and how to deal with suspected COVID-19 cases.

Nearly all healthcare respondents (95\%) had received guidance documents for COVID-19 care albeit some are incomprehensive. A few respondents indicated that their guidelines contained just the symptoms and signs of COVID-19. Other concerns identified delays in providing the guidelines to health workers. Respondents in the Anglophone Regions complained that the guidelines received were in the French language, which they did not understand.

\subsection{Need for Social Cohesion}

An aspect of social capital examined in this research was stigmatisation. Almost all the respondents (96.4\%) acknowledged social stigma associated with COVID-19. The consequences mentioned include that potential non-symptomatic patients are ashamed to be diagnosed of COVID-19 and not seeking medical attention; publics is shunning medical facilities for fear of contamination, which has led to a drop in routine vaccinations; some health professionals keep away from patients with the disease and families of COVID19 patients are also stigmatised. A respondent was unequivocal," There is serious self-stigma and social/public stigma has been a major challenge in COVID-19 testing and management of patients..." This problem was identified by Cameroon's Centre for Disease Control who engaged in a health promotion campaign to counteract COVID-19 misinformation and stigma (CDC, 2020).

\subsection{Communication Mechanisms}

Treatment protocols was gauged and yielded 89.3\% affirmative responses. An insight on the COVID-19 protocol instituted by the MPH was captured: it varies with symptomatology and severity; links patients' profile to appropriate treatment sites; severe cases to be referred to specialised COVID-19 treatment facilities; and the recommended drug are hydroxychloroquine, azithromycin, vitamin $\mathrm{C}$, chloroquine, lovenox, oxygen, zinc, paracetamol and anticoagulants/anti-inflammatory drugs. The provision of protocols in French to English speaking health workers was expressed succinctly by one respondent, "The Covid-19 treatment protocol...is unfortunately in French and so adoption is limited to those who can comprehend French." This respondent recommended translation of such documents for the consumption of Englishspeaking Cameroonians.

Regarding sensitisation/information dissemination on COVID-19, 77\% of the health actors believe the government has exerted much effort to educate the public. Nevertheless, a few respondents critical of governments sensitisation measures asserted that "...coordination of public sensitisation is poor..." and "...sometimes contradictory messages are being communicated to the public." Attention was drawn to the fact that the populace in the conflict affected areas have difficulty accessing COVID-19 sensitisation. Some respondents contend that public sensitisation is politicized with minimal involvement of health workers and local community education is ineffective due to non-provision of funds for health promotion activities. A respondent was clear on this point, "Only flyers and posters were provided with no funds to help mobilizers and distribute them in the community." The view of this respondents was that more has to be done to sensitise and educate local communities. 
Findings on public's understanding of COVID-19 risks produced low results (7.4\%, Figure 7). This is contradictory to the health workers' high perception of sensitisation implying the populace may be getting messages but not being educated on the effects and threats posed by the pandemic. The reasons provided are misinformation, myths, misconception, negligence, poor knowledge/understanding of the virus, disbelief that the virus exists, that the disease is mild or a hoax/propaganda, reduced risk perception from being lethal to less harmful, perceived government's lack of stringent enforcement measures to mean the disease is not dangerous and that some people believe COVID-19 is a government conspiracy.

\subsection{Governance}

Overall, respondents painted a bleak picture of government's management of the pandemic (Figure 8). Their justification are poor inter-ministerial stakeholder cooperation; initial incomprehensive guidance provided to health workers; hyper-centralised pandemic management; non-provision of basic resources to local level (District) hospitals; much constraints to access resources for COVID-19 care; that committees charged with the pandemic management had more politicians than health professionals/scientists; weak supply chain system; insufficient health staff; poor logistic network and inadequate policies/preparedness for a pandemic.

Some respondents blamed poor decision making on lack of adequate medical expertise in the decisionmaking process. Two succinct comments captured this viewpoint, "...administrators instead of public health experts stole the show..."and "...the management of the pandemic has been more political than medical..."

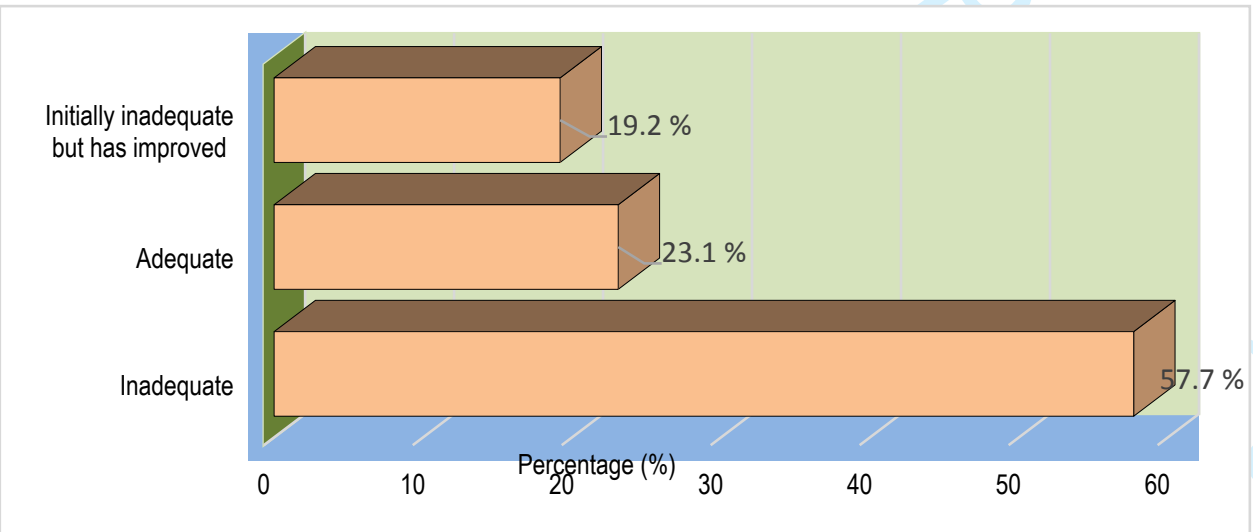

Figure 8: Government's management of the pandemic

Regarding the treatment of frontline health workers, most respondents felt the government was slow to react to their concerns. The research uncovered that health workers are unmotivated due to lack of financial 
incentives .Their satisfaction on available communication channels to raise concerns produced a split verdict. One respondent said he could discuss about "most things...but for the financial aspect." Another reveal that if you want to complain, "...you are cautioned not to talk like that" and a few said the response depended on the request.

The respondents recommended that the government should be proactive in strengthening the health system, institute a solid COVID-19 coordination mechanism; secure sufficient funds for subsequent epidemics/pandemic; reduce dependency on foreign aid; curtail bottlenecks in the health system; decentralise health care and provide more allowance for traditional medicine in the country.

\subsection{Trust}

Institutional and patient-provider trust constitutes this section. These were assessed through gauging public confidence on the health sector's ability to manage COVID-19 (Figure 9) and the public's response to preventive measures (Figure 10). Both results reveal lack of complete confidence and/or trust in the health

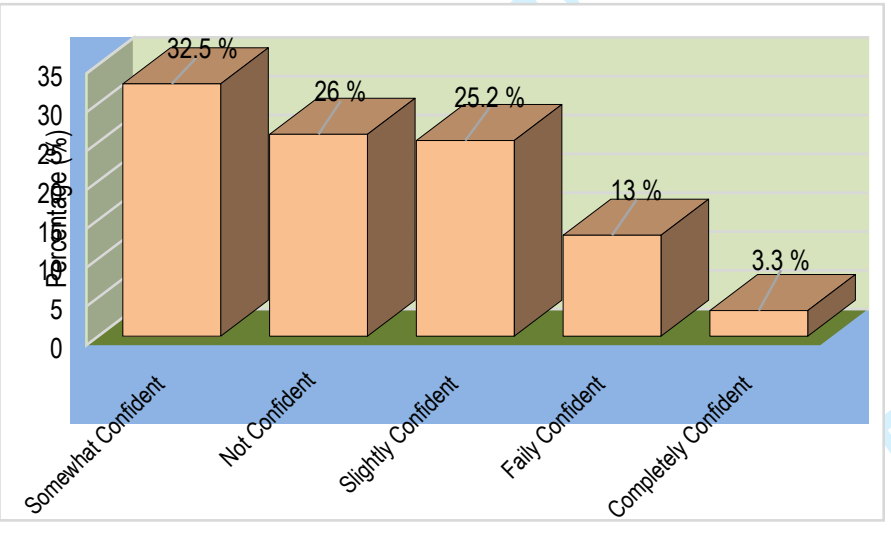

Figure 9: Public's confidence in the health system to treat COVID-19 patients

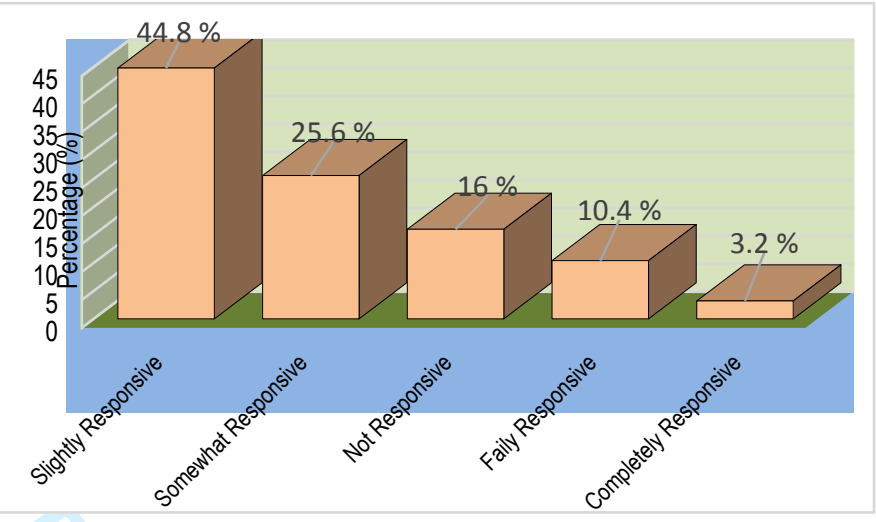

Figure 10: Public's response to preventive measures

system. In fact, hundreds of patients admitted in hospitals have fled and thousands of others are avoiding hospitals in Cameroon for fear of catching coronavirus when cases began to rise exponentially in April (Kindzeka, 2020).

\subsection{Summary of Findings}

A summary of the key findings is presented in Table II. The findings have been assessed against the key activities/resources of the HSREID elements to determine resilience of Cameroon's COVID-19 response. The overall assessment reveals non-compliance in almost all the key activities of the HSREID elements. indicating a low resilience to the COVID-19 pandemic.

\section{Table II here}

\subsection{Discussion}

Despite government's commendable effort to combat the COVID-19 pandemic, significant constraints persist, including in operational procedures, which arguably could have been learnt from past experiences. For instance, delays to institute lockdown measures after the first cases were detected may have led to more infections.

The acute centralisation of Cameroon's health system in the nation's political and economic capitals is a huge blow to the COVID-19 pandemic management at the Regional and Divisional/District levels. 
Decentralisation of the response is urgently required to enable District Hospitals have access to qualified staff and basic diagnostic/safety equipment. Insufficient PPE and critical care units raises the question of contingency planning for infectious diseases. Ideally, the pre-epidemic period should be characterised by stockpiling of basic materials, training/simulation exercises, heath risk transfer measures and acute situation awareness for infectious diseases (Madhav, 2018).

Notwithstanding government's effort to sensitise the public, more emphasis should be placed on understanding the risks posed by COVID-19, the detrimental effects of social stigma and harnessing public trust in the health system. Whilst the effective enforcement of restrictive infection control measures is an elusive prospect since Cameroon is not a welfare state that can financially support its citizens during lockdowns, effective education would enable the population to make rational decisions and respect infection control measures.

Since English and French are the official languages in Cameroon, it is relevant to communicate vital health information in the language the population would understand. Arguably, this is part of the reason why government's messages of national solidarity to fight the COVID-19 pandemic is afloat in the conflictridden Anglophone regions where the population has been at the mercy of militia groups and the security forces for more than four years now. One wonders whether the traumatised people living in that region are wary about contracting COVID-19 or being caught in a crossfire! Arguably, government's ability to successfully combat COVID-19 and subsequent epidemics will depend on how they can speedily resolve the Anglophone Crisis.

The findings of this research have significant governance implications for public health crises. The identified challenges are rooted in Cameroon's fragile health care system with consequences for interventions during health crises. Political commitment and creative measures that involve aligning the identified constraints with investments in Cameroon's health infrastructure is required to ensure resilience against future shocks and crises. Ultimately, a stronger health sector sets the pace for a stronger health crisis response and consequently higher resilience to an epidemic/pandemic. The reverse is also true, as evidenced in this research.

\subsection{Conclusion}

This article has used the HSREID framework to provide a snapshot of Cameroon's resilience to the COVID19 pandemic. The motive was to diagnose limitations in dealing with the pandemic for optimal health care provision. The empirical analysis demonstrate that Cameroon is not adequately resilient to the COVID-19 pandemic (see Table II). Notable are the country's weak healthcare infrastructure with associated scarce resources; governance issues and related challenges in communication, incentivising frontline health workers and lack of trust/confidence in the health system.

As community transmission of COVID-19 continues to take hold in Cameroon, enhanced measures to fight the pandemic are inevitable to mitigate infections and disruptions to the country's health systems. The latter could unwind decades of progress against the treatment of other tropical and infectious diseases endemic to the country. These findings provide a roadmap for Cameroon to ameliorate the identified constraints in responding to the COVID-19 pandemic and build a more resilient, highly responsive and functional health systems in the long-term. The short-term priority, however, is to triumph over COVID-19. To achieve this desirable outcome, sustained political commitment will be required to provide the much-needed resources.

This article contributes to a growing, yet limited, knowledge on the application of HSR frameworks in assessing contemporary health crises. It also demonstrates that more research is needed in Cameroon's health infrastructure/systems, especially on policy and implementation processes during health crises; how socio-economic and cultural factors impact the populace affected by COVID-19 in order to better enhance governance strategies for future outbreaks; how best to implement social distancing in rural settlements characterised by big households sharing limited sanitation facilities and to understand better how to mitigate 
myths and gain government trust in the health system. Research in these areas is vital for optimal implementation of public health interventions during health crises in resource limited countries.

\section{References}

Agbor, E. and Tambi, M. (2014), “ Determinants of HIV/AIDs epidemics prevalence in Cameroon”, International Journal of Research and Review, Vol 1 No. 2, pp. 8-19. available at: https://www.ijrrjournal.com/IJRR_Vol.1_Issue2_October2014/2.pdf (accessed June 24 2020)

Ager, A., Lembani, M., Mohammed, A., Ashir, G., Abdulwahab, A., Pinho, H., Delobelle, P. and Zarowsky, C. (2015), "Health service resilience in Yobe state, Nigeria in the context of the Boko Haram insurgency: a systems dynamics analysis using group model building", Conflict and Health, Vol 9 No 30, pp.1-14. https://doi.org/10.1186/s13031-015-0056-3

Barasa, E., Cloete, K. and Gilson, L. (2017), "From bouncing back, to nurturing emergence: Reframing the concept of resilience in health systems strengthening", Health Policy and Planning, Vol 32 No 2017, pp. 91-94. https://doi.org/10.1093/heapol/czx118

Blanchet, K., Nam, L., Ramalingam, B. and Pozo-Martin, F. (2017). “Governance and capacity to manage resilience of health systems: towards a new conceptual framework", International Journal of Health Policy and Management, Vol 6 No.8, pp. 431-435. https://doi.org/10.15171/IJHPM.2017.36

CDC (2020), CDC programs in Cameroon pivot to COVID-19 response, available at: https://www.cdc.gov/globalhealth/stories/cameroon-covid-response.html (accessed 18 July 2020)

European Commission (2014), "Communication from the Commission: On effective, accessible and resilient health systems. Brussels". Available at: https://eur-lex.europa.eu/legalcontent/EN/TXT/HTML/?uri=CELEX:52014DC0215\&from=EN (accessed 21 August 2020)

Hammarberg, K., Kirkman, M. and Lacey, S. (2016), "Qualitative research methods: when to use them and how to judge them", Human Reproduction, Vol.31 No.3, pp. 498-501.

http://doi.org/10.1093/humrep/dev334

HRW (2020), Cameroon: Investigate, distribute health fund, available at:

https://www.hrw.org/news/2020/06/12/cameroon-investigate-distribute-health-fund\# (accessed 25 June 2020)

IMF (2020), IMF executive board approves a US\$226 million disbursement to Cameroon to address the impact of the COVID-19 pandemic, available at:

https://www.imf.org/en/News/Articles/2020/05/04/pr20205-cameroon-imf-exec-board-approves-us226m-disbursement-address-impact-covid19-pandemic (accessed July 18 2020)

Kieny, M., Evans, D., Schmets, G. and Kadandale, S. (2014). "Health-system resilience: reflections on the Ebola crisis in western Africa", Bulletin of the World Health Organisation, Vol 92 No 850, http://dx.doi.org/10.2471/BLT.14.149278

Kindzeka, M. (2020), "Cameroon patients flee hospitals as COVID-19 cases increase", available at: https://www.voanews.com/covid-19-pandemic/cameroon-patients-flee-hospital-covid-19-cases-increase. (accessed June 28 2020)

Kindzeka, M. (2018), “Cameroon doctors overwhelmed with patients", vailable at : https://www.voanews.com/africa/cameroon-doctors-overwhelmed-patients. (accessed 11 June 2020) 
Kutzin, J. and Sparkes, S. (2016). "Health systems strengthening, universal health coverage, health security and resilience", Bulletin of the World Health Organization, Vol 94 No 1, http://dx.doi.org/10.2471/BLT.15.165050

Kluberg, S., Mekaru, S., Mclver, D., Madoff, L., Crawley, A., Smolinski, M. and Brownstein, J. (2016), "Global capacity for emerging infectious disease detection, 1996-2014", Emerging and Infectios Diseases, Vol. 22 No10, pp.1-9. http://dx.doi.org/10.3201/eid2210.151956

Madhav, N., Oppenheim, B., Gallivan, M., Mulembakani, P., Rubin, E. and Wolfe, N. (2018), "Pandemics: risks, impacts and mitigation", in Jamison, D., Gelband, H., Horton, S., Jha., R., Laxminarayan, R., Mock, C. and Nugent, R. (Eds), Disease Control Priorities: Improving Health and Reducing Poverty, World Bank, Washington DC. https://doi.org/10.1596/978-1-4648-0527-1_ch17.

Martineau, F. (2016). "People-centred health systems: building more resilient health systems in the wake of the Ebola crisis", International Health, Vol 8 No 5, pp. 307-309.

https://doi.org/10.1093/inthealth/ihw029

MPH (2020), DONATE, available at: http://covid19.MPH.cm (accessed June 15 2020)

MPH (2016), National health development Plan, Ministry of Public Health, Yaoundé: Cameroon

Nde, C., Raymond, A., Saidu, Y., Cheng, N., Nzoubontane, D., Atemnkeng, J. and Mbacham, W. (2019), "Reaching universal health coverage by 2035: Is Cameroon on the track?", Universal Journal of Public Health, Vol. 7 No.3, pp.110-117. http://doi.org/10.13189/ujph.2019.070304

Ngeh, E. and Kuaban, C. (2020), "COVID-19: challenges and the impact on care in clinical settings in Cameroon", The Pan African Medical Journal, Vol 35 No 2, pp.

https://doi.org/10.11604/pamj.supp.2020.35.2.24929

Njonnou, S., Lekpa, F., Ouankou, C., Balti, E. and Choukem, S.(2020), “The challenge of COVID-19 case identification and ascertainment in sub-Saharan Africa: the case of Cameroon", The Pan African Medical Journal, Vol 35 No 2, https://doi.org/10.11604/pamj.supp.2020.35.2.24368

NOPH/MPH, (2017), Life expectancy at birth, available at: http://onsp.minsante.cm/profiles_information/index.php/Cameroon:Life_expectancy at_birth/en (accessed August 20 2020)

OCHA (2020), CAMEROON: COVID 19 emergency situation report No. 03, available at: https://reliefweb.int/sites/reliefweb.int/files/resources/cameroon_covid19_emergency_situation_report_no . 03.pdf (accessed June 13 2020)

Olu, O. (2017). "Resilient health system as conceptual framework for strengthening public health disaster risk management: An African viewpoint", Frontiers in Public Health, Vol 5, pp. 1-6. https://doi.org/10.3389/fpubh.2017.00263.

Palagyi, A., Marais, B., Abimbola, S., Topp, S., McBryde, E. and Negin, J. (2019), "Health system preparedness for emerging infectious diseases: A synthesis of the literature", Global Public Health, Vol. 14 No.12, pp. 1847-1886. https://doi.org/10.1080/17441692.2019.1614645

ReBUILD (2016). Health systems resilience: A complex adaptive systems analysis, available at: https://rebuildconsortium.com/our-research/research-projects/additional-research-themes/health-systemsresilience/(accessed August 27 2020) 
Tamfu, A. and Lietbouo, A. (2020), "Feature: Schools in Cameroon gradually reopen amidst COVID-19 pandemic", avialable at: http://www.xinhuanet.com/english/2020-06/02/c 139105960.htm (accessed August 23 2020)

Turenne, C., Gautier, L., Degroote, S., Guillard, E., Chabrol, F. and Riddle, V. (2019), "Conceptual analysis of health systems resilience: A scoping review", Social Science and Medicine, Vol 232, pp. 168-180. https://doi.org/10.1016/j.socscimed.2019.04.020.

UN (2020), "World's most vulnerable countries lack the capacity to respond to a global pandemic", available at: https://www.un.org/ohrlls/news/world's-most-vulnerable-countries-lack-capacity-respondglobal-pandemic-credit-mfdelyas-alwazir (accessed July 26 2020)

UNISDR (2005), Hyogo framework for action 2005-2015: building the resilience of nations and communities to disasters", available at: https://www.unisdr.org/2005/wcdr/intergover/official-doc/Ldocs/Hyogo-framework-for-action-english.pdf (accessed February 14 2020)

UNISDR (2009), UNISDR Terminology on Disaster Risk Reduction, available at: http://www.unisdr.org/we/inform/terminology. (accessed May 14 2019)

UNISDR (2015), Sendai framework for disaster risk reduction 2015-2030", available at: https://www.preventionweb.net/files/43291 sendaiframeworkfordrren.pdf (accessed October 02 2018)

World Bank (2020), Cameroon, available at: https://data.worldbank.org/country/cameroon?view=chart (accessed August 08 2020)

WHO (2015), Operational framework for building climate resilient systems, available at https://apps.who.int/iris/bitstream/handle/10665/189951/9789241565073 eng;jsessionid=F618BB436A2 EBBDD2FFCEBF4FFC7F6D8? sequence=1. (accessed July 17 2020)

WHO (2016), Health analytical profile:Cameroon - 2016, avaiilable at: https://www.afro.who.int/publications/health-analytical-profile-cameroon-2016 (accessed June 07 2020)

WHO (2018), Communicating risk in public health emergencies: A WHO guideline for emergency risk communication (ERC) policy and practice, available at: https://apps.who.int/iris/bitstream/handle/10665/259807/9789241550208-eng.pdf?sequence=2 (accessed 10 August 2020)

WHO (2020), Strengthening health systems resilience: key concepts and strategies, available at: https://apps.who.int/iris/bitstream/handle/10665/332441/Policy-brief\%2036-1997-8073-eng.pdf (accessed 21 August 2020) 
Table I

Table I: Table showing the HSREID framework

\begin{tabular}{|c|c|c|c|}
\hline Framework & Constructs & Elements & Key Activities/Resources \\
\hline 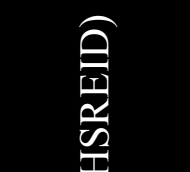 & \multirow{4}{*}{ 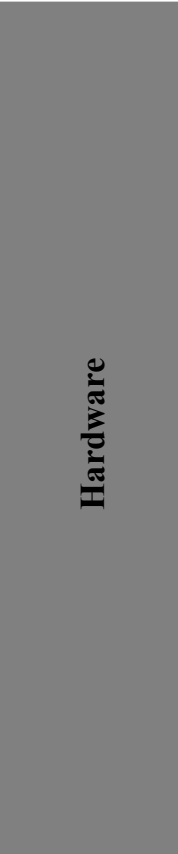 } & Infrastructure and Medical Supply & $\begin{array}{l}\text { - Health care facilities } \\
\text { - Equipment } \\
\text { - Laboratory systems } \\
\text { - Essential medicines \& technologies }\end{array}$ \\
\hline 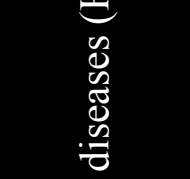 & & Human Capital/Workforce & $\begin{array}{l}\text { - Key skill sets } \\
\text { - Health workforce numbers } \\
\text { - Competency (training) } \\
\text { - Deployment of workforce }\end{array}$ \\
\hline 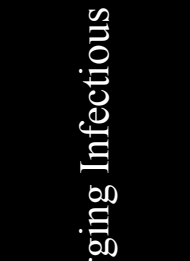 & & Surveillance & $\begin{array}{l}\text { - Human disease surveillance } \\
\text { - Animal and zoonotic disease } \\
\text { surveillance } \\
\text { - Screening and referral processes } \\
\text { - Vector control programmes } \\
\text { - Prediction modelling }\end{array}$ \\
\hline 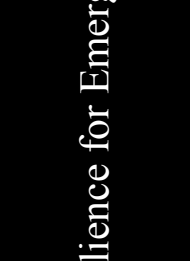 & & Communication Mechanisms & $\begin{array}{l}\text { - National reporting and notification } \\
\text { systems } \\
\text { - Health facility protocols } \\
\text { - Laboratory protocols } \\
\text { - Media and public health messages } \\
\text { - Community engagement }\end{array}$ \\
\hline 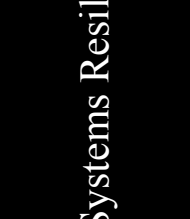 & \multirow{2}{*}{ 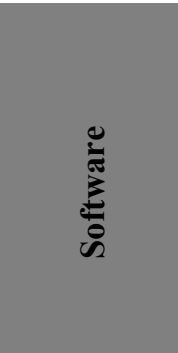 } & Governance & $\begin{array}{l}\text { - Health leadership } \\
\text { - Multisectoral coordination } \\
\text { - Partnerships } \\
\text { - Health worker management and } \\
\text { suppor }\end{array}$ \\
\hline 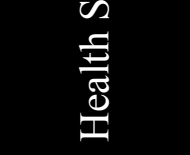 & & Trust & $\begin{array}{l}\text { - Institutional trust } \\
\text { - Workplace trust } \\
\text { - Patient-provider trust }\end{array}$ \\
\hline
\end{tabular}

Source: Authors, adapted from Palagyi et al. (2019).

Table II

Table II: Table showing summary of the findings and their compliance with the HSREID framework

\begin{tabular}{|l|l|l|}
$\begin{array}{c}\text { Elements of the HSREID } \\
\text { Framework }\end{array}$ & \multicolumn{1}{|c|}{ Key Activities/Resources } & \multicolumn{1}{c|}{$\begin{array}{c}\text { Compliance with the HSREID } \\
\text { Framework or Findings }\end{array}$} \\
\hline \multirow{2}{*}{$\begin{array}{l}\text { Infrastructure and } \\
\text { Medical Supply }\end{array}$} & Health Care Facilities & Limited \& Inadequate \\
\cline { 2 - 3 } & Equipment & Shortage and inappropriate \\
\hline & Laboratory Systems & Limited and Inadequate \\
\hline & Essential Medicines \& Technology & Insufficient \\
\hline \multirow{2}{*}{ Human Capital/Workforce } & Key Skill Sets & Insufficient \\
\cline { 2 - 3 } & Health Workforce Numbers & Low \\
\hline & Competency (Training) & Insufficient \\
\hline & Deployment of Workforce & Inadequate \\
\hline
\end{tabular}




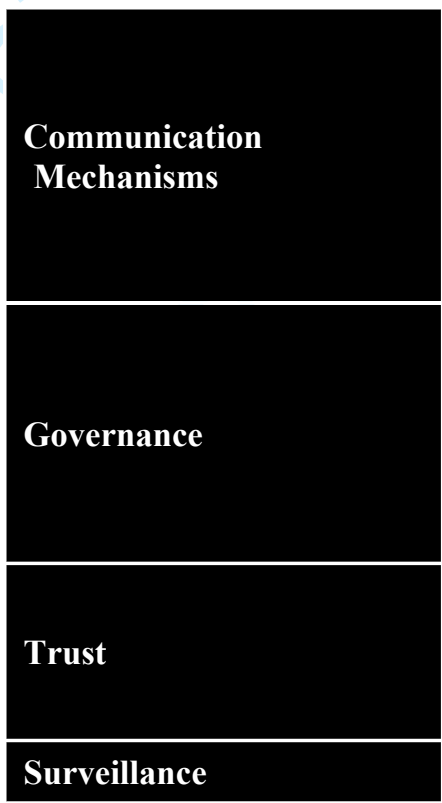

\begin{tabular}{|l|l|}
\hline National Reporting and Notification & Inadequate \\
\hline Health Facility Protocols & Inadequate \\
\hline Laboratory Protocols & Unsatisfactory \\
\hline Media \& Public Health Messages & Satisfactory \\
\hline Community Engagement & Unsatisfactory \\
\hline Health Leadership & Unsatisfactory \\
\hline Multisectoral Coordination & Poor \\
\hline Partnership & Weak \\
\hline $\begin{array}{l}\text { Health Worker Management \& } \\
\text { Support }\end{array}$ & Unsatisfactory \\
\hline Institutional Trust & Moderate \\
\hline Workplace Trust & Low \\
\hline Patient Provider Trust & Low \\
\hline \multicolumn{1}{|c|}{ Pre pandemic disease surveillance not applicable to research } \\
\hline
\end{tabular}

Source: Authors. 